\title{
Comparison of conventional frying and microwave frying of beef patty: effect on oil absorption, texture, physical and chemical properties
}

\author{
Noor Hidayati, R., Nurul Najihah, I. and *Norazatul Hanim, M.R. \\ Food Technology Division, School of Industrial Technology, Universiti Sains Malaysia, 11800, Penang, \\ Malaysia
}

\begin{abstract}
Article history:
Received: 6 December 2020 Received in revised form: 4 January 2020

Accepted: 8 March 2021

Available Online: 27 June 2021
\end{abstract}

\section{Keywords:}

Food engineering,

Food processing,

Thermomechanical properties,

Beef patty,

Frying quality,

Microwave frying

\section{DOI:}

https://doi.org/10.26656/fr.2017.5(3).640

\begin{abstract}
A comparative study was performed to evaluate the effect of conventional and microwave frying on the quality attributes (moisture, fat, textural properties, colour, and cooking yield) of the beef patty. Experiments were conducted by cooking the beef patties using conventional and microwave frying in two different types of oil (palm oil and corn oil). Two microwave power levels were used (50\% and 70\%). Microwave frying beef patty showed a significant difference in terms of moisture content, hardness, lightness $\left(\mathrm{L}^{*}\right)$ and also cooking yield compared to conventional frying. The oil absorption can be reduced when the beef patty was cooked using a microwave. Beef patty fried with the highest microwave power level $(70 \%)$ by using corn oil has the least oil absorption $(18.44 \pm 1.04 \%)$. The theory of higher moisture loss higher oil uptake does not correspond in this experiment since low-fat content were observed as the moisture decreased for all the beef patties fried using a microwave. Analysis of the hardness of beef patty showed that microwave frying beef patty (corn oil) at a power level of 50\% (MF 50\%) has the hardest texture $(35.48 \pm 2.10 \mathrm{~kg})$. Microwave frying beef patty has a lower cooking yield $(56.05 \pm 2.23$ to $71.30 \pm 0.89 \%)$ compared to conventional frying $(86.12 \pm 0.45$ to $88.60 \pm 0.04 \%)$. It is also found that there was no significant effect of type of cooking oil on the quality attributes of fried beef patties while different frying techniques were observed to affect the quality of patty.
\end{abstract}

\section{Introduction}

Frying is one of the fastest cooking methods since it requires a high temperature $\left(150^{\circ} \mathrm{C}\right.$ to $\left.190^{\circ} \mathrm{C}\right)$ to cook the food product, thus shortening the cooking time. Frying can give desirable flavour, colour and also crispy texture which resulted from the simultaneous heat and mass transfer of oil that acts as heat transfer medium (Choe and Min, 2007). However, the amount of fat absorbed by the food leaves a negative impact on the human body. Fried food has become a concern due to its negative effect on humans' health where excess oil is the major problem (Ziaiifar et al., 2008). The reduction of fatcontaining food is crucial to prevent cardiovascular disease (CVD) and obesity among consumers. Thus, an effort to develop a better method to understand reducing oil uptake of food products during the frying process is required. Numerous alternatives to frying had been studied to reduce fat or oils absorption including oven frying and microwave frying (Su et al., 2016), vacuum frying (Su et al., 2016) and air frying method (Shaker, 2015).
Beef patties are usually made from lean cow meat. In some countries such as England, it is referred to as ground meat. In Malaysia, the processed burger patties are compressed and moulded into a disc shape with a thickness of one centimetre and can be bought from any retail market (Wong et al., 2011). According to Wong et al. (2011), raw hamburger contains harmful bacteria such as Listeria monocytogenes and Escherichia coli O15:H17 that can cause foodborne illness. In order to fix that, the United State Department of Agriculture (USDA) has come out with guidelines to ensure the patties are safe to be consumed. The internal temperature of a beef patty should reach $71^{\circ} \mathrm{C}$ or more to ensure a 12-log reduction of bacteria (Food Safety, 2009). On the other hand, the consumptions of fat, saturated fatty acids, cholesterol and also sodium in meat can cause chronic diseases such as heart disease and hypertension (Zzaman et al., 2013). Hence, the frying of meat and meat products is essential to ensure a palatable and safe product can be achieved (Tornberg, 2005).

In this research, the microwave frying method was 
chosen as an alternative method to the conventional frying of the beef patty. The previous study by Naik et al. (2017) showed that microwave frying of french fries had less oil absorption (25.48\%, 29.05\%, 68.98\%) compared to conventional frying $(41.28 \%, 37.22 \%$, $71.82 \%$ ) for sunflower, corn and groundnut oil, respectively. Microwave has less frying time which may lead to less oil absorption compared to conventional frying. The interaction between microwave and polar water molecules in the food products causes it to absorb the wave energy, therefore it can quickly heat the food. The heat produced may give a sharp mass transfer due to the internal pressure steam which causes a drying effect without concerning overheating the surface of the food (Sansano et al., 2018). The effect of microwave power on fatty acid raises a concern. Furthermore, it was found that microwave frying can hardly modify the fatty acid profiles on chicken and beef patties (Naik et al., 2017).

Many researchers emphasized reducing oil absorption using plant-based products such as potato chips (Su et al., 2016) and french fries (Sansano et al., 2018). The research on microwave frying of meat-based product is still scarce. In this study, palm oil and corn oil were chosen as a frying medium for the beef patty. Palm oil was selected since it is the most common frying oil used worldwide due to its production efficiency. It also has a low content of polyunsaturated fatty acid (10\%) which contributes to its stability features (MPOC, 2012). Palm oil also contains Vitamin E and has high resistance towards oxidation, produces a less volatile compound, retains the flavour of the food, is stable at high temperature and most importantly it does not contain trans-fat since there is no hydrogenation process (May and Nesaretnam, 2014). As for corn oil, it has a high smoke point which claimed to have a good effect on health (Fasina and Colley, 2008).

The aim of this study is to evaluate the performance of microwave frying to reduce oil uptake in beef patty as compared to the conventional frying method. The parameters that were under investigations are different types of oil and microwave power levels. The effect of microwave frying on beef patty was analyzed based on frying quality attributes such as moisture content, fat content, colour, hardness and cooking yield. The result of this study might be useful in reducing fat and oil uptake during the preparation of beef patty for the domestic and food service.

\section{Materials and methods}

\subsection{Raw materials}

Beef patties that were used were the commercial beef patty (Burger Lembu, Azmy, Malaysia) purchased in a local supermarket. The beef patties were stored in a freezer at $-18^{\circ} \mathrm{C}$ before further use. Refined cooking oil (Buruh, Malaysia) and corn oil (Vecorn, Malaysia) purchased from local supermarkets were used to fry the beef patties. Petroleum ether (QRec, Malaysia) was used in the Soxhlet extraction method in oil absorption analysis.

\subsection{Thawing of beef patty}

Thawing of beef patty was conducted based on Laack et al. (1996). A top freezer refrigerator (LG, South Korea) was used to thaw beef patties. Frozen beef patties were thawed at $4{ }^{\circ} \mathrm{C}$ for $24 \mathrm{hrs}$ prior to cooking. Thawing was done to allow myoglobin in the meat to be converted into metmyoglobin which enhances the brownish colour of beef patty when cooking (Bigner-George and Berry, 2000).

\subsection{Frying process}

Beef patties were cooked by two different methods which are conventional frying and microwave frying. The time required to cook the beef patty was determined by conducting a preliminary experiment. Since there is no specific time to ensure the beef patty was cooked and safe to be consumed, the total time taken to cook the beef patty was by complying with the guidelines by the United State Department of Agriculture (USDA) whereby its requirement for the internal temperature to ensure 12-log reduction in beef patty must be more than $71.1^{\circ} \mathrm{C}$. Two different types of oil were used for frying which was palm oil and corn oil.

\subsubsection{Conventional frying}

A cooking plate (Tefal Compact CB500) was used to cook beef patties conventionally. Initially, the cooking plate was turned on to allow it to heat up before cooking by adjusting the thermostat to level 3 . A volume of 20 $\mathrm{mL}$ of cooking oil (palm oil and corn oil) was measured and poured onto the cooking plate. The temperature of the oil was measured using a laser thermocouple to ensure it had reached $180^{\circ} \mathrm{C}$ before frying. The beef patty was allowed to cook for 2 mins for one side before flipping. The frying process was done in duplicate for one type of oil.

\subsubsection{Microwave frying}

In microwave frying, oil acts as a heat transfer medium rather than air and microwave frying were done using a microwave oven (AV-1500V) (Sharp, Healsio). Approximately $20 \mathrm{~mL}$ of cooking oil (palm oil and corn oil) were measured using a $50 \mathrm{~mL}$ measuring cylinder. The oil was poured into the $500 \mathrm{~mL}$ microwavable glass container and the thawed beef patty was placed inside 
the glass container. The microwave oven setting was adjusted to $50 \%$ and $70 \%$ of power level, respectively. The time was set for 2 mins for one side of the beef patty before flipping. The microwave frying was done in duplicate for each oil.

\subsection{Characterization of beef patty}

\subsubsection{Moisture analysis}

Moisture content in cooked beef patty was determined based on AOAC Method 934.0: Air-Oven Method (AOAC, 2000). Moisture dish and lids were cleaned and dried in an oven (Memmert UL40, Germany). Every moisture dish and lid were weighed and the data was recorded. The beef patty samples were homogenized using a mortar and pestle. Approximately $10 \mathrm{~g}$ of the sample was weighed into a moisture dish and then placed in the oven at $100-105^{\circ} \mathrm{C}$ until a constant weight was obtained. Before the moisture dish is weighed, it was cooled in the desiccator. The moisture dish was weighed together with the lid. Moisture content can be calculated as below:

Moisture Content $=\frac{\text { Weight of wet sample-Weight of dried sample }}{\text { Weight of wet sample }} \times 100 \%$

\subsubsection{Fat analysis}

Fat content or oil uptake in cooked beef patty was determined based on AOAC Method 963.15: Soxhlet Extraction Method (AOAC, 2000). The solvent used in extracting the fat is petroleum ether with a $60^{\circ} \mathrm{C}$ boiling point. The Soxhlet extraction flask was weighed and the data were recorded. Approximately $3 \mathrm{~g}$ of samples were weighed into the extraction thimble and cotton were used to cover the sample. The extraction thimble was placed in the Soxhlet extractor and petroleum ether was poured into the Soxhlet extractor until it siphons and this process was repeated three times. The condenser and steam bath were turned on and the samples were allowed to reflux for two hours. The extraction thimble was taken out from the Soxhlet extractor when the process is finished. The remaining petroleum ether was allowed to be distilled out from the Soxhlet extraction flask using a steam bath until it dried up. Then, the extraction flask was placed in the oven for an hour at $100-105^{\circ} \mathrm{C}$. The extraction flask was then moved into a desiccator to cool down and later weighed. Fat content can be calculated as below:

Fat Content $=\frac{\text { Weight of flask with sample-Weight of empty flask }}{\text { Weight of sample }} \times 100 \%$

\subsubsection{Colour measurement}

Colour measurement was done by using a spectrophotometer (Minolta Spectrophotometer CM$3500 \mathrm{~d}$, USA). The cooked beef patty sample was cut into small cubes at approximately $3 \times 3 \mathrm{~cm}$. Calibration was done using a zero calibration box and white calibration plate. The colour reading that was performed includes Lightness $\left({ }^{*} \mathrm{~L}\right)$, redness $\left({ }^{*} \mathrm{a}\right)$ and yellowness $\left({ }^{*} \mathrm{~b}\right)$.

\subsubsection{Texture analysis}

The hardness of the beef patty was analyzed by using Texture Analyzer TA-XT and TA-Hdi Texture Analyzer (Stable Microsystem, UK) following Bourne (1978) procedures with modifications. The beef patties that were cooked using microwave and conventional frying were prepared prior to analysis. The texture was determined using Texture Profile Analyzer (TPA) test type and the hardness was analyzed. The load cell used was $30 \mathrm{~kg}$ and the type of probe used was compression platen $75 \mathrm{~mm}$. The setting used for TPA was $3.00 \mathrm{~mm} / \mathrm{s}$ for pre and post -test speed and $1.00 \mathrm{~mm} / \mathrm{s}$ for test speed. The trigger force used was $10 \mathrm{~g}$ and with a distance of $75 \mathrm{~mm}$. The hardness is the resistance ( $\mathrm{g}$ ) at maximum compression during the first compression or first bite.

\subsubsection{Cooking yield}

The cooking yield was determined according to the method described by Serdaroğlu (2006). The beef patty was cooked using the hot plate and a stopwatch was used to record the cooking time. The raw beef patty was thawed at $4^{\circ} \mathrm{C}$ for $24 \mathrm{hrs}$ prior to frying. The uncooked beef patty was initially weighed and followed by the frying process which was done for 4 mins for each patty. After frying, the beef patty was weighed again and the data was recorded. Cooking yield can be calculated as below:

Cooking Yield $=\frac{\text { Weight of beef patty after frying }}{\text { Weight of beef patty before frying }} \times 100 \%$

\subsection{Statistical analysis}

Data obtained were analyzed by using Statistical Packages for Social Science (SPSS) software version 22.0 (SPSS Inc., Illinois, USA). Duncan's test with twoway analysis of variance (ANOVA) was used with the significant level at $\mathrm{P}<0.05$.

\section{Results and discussion}

\subsection{Moisture and fat content analysis}

In this study, beef patties that were fried using conventional frying and microwave frying with power levels of $50 \%$ and $70 \%$ were denoted as CF, MF $50 \%$ and MF70\% respectively. The initial moisture and fat content of raw beef patty is $50.73 \pm 0.20 \%$ and $28.24 \pm 2.29 \%$, respectively. Based on the results shown in Table 1, conventional frying, $\mathrm{CF}$ has the highest moisture content after the frying process followed by $\mathrm{MF} 50 \%$ and $\mathrm{MF}$ $70 \%$ for both types of oil. There was a significant effect of different frying techniques $(p<0.05)$ on the final moisture content. However, there was no significant effect on the different types of oil $(p>0.05)$ on the moisture content within a similar frying technique. The final fat content of conventional frying, $\mathrm{CF}$ showed the 
highest oil absorption (34.00 $\pm 6.23 \%$ ) followed by MF $50 \%(25.95 \pm 0.92 \%)$ and lastly MF $70 \%(20.50 \pm 3.80 \%)$. However, no significant effect was observed between different frying techniques for corn oil-fried beef patties $(p>0.05)$ on its final fat content. On the other hand, different types of oil did not affect the final fat content of all frying techniques based on its insignificant difference $(\mathrm{p}<0.05)$ shown in Table 1.

Table 1. Moisture content, fat content composition and hardness of fried beef patties

\begin{tabular}{cccc}
\hline Response & Frying & Palm oil & Corn oil \\
\hline \multirow{2}{*}{ Moisture } & CF & $48.87 \pm 0.80^{\mathrm{c}, \mathrm{A}}$ & $49.45 \pm 1.03^{\mathrm{c}, \mathrm{A}}$ \\
content (\%) & MF 50\% & $37.23 \pm 1.10^{\mathrm{b}, \mathrm{A}}$ & $37.47 \pm 1.63^{\mathrm{b}, \mathrm{A}}$ \\
& MF 70\% & $22.70 \pm 3.40^{\mathrm{a}, \mathrm{A}}$ & $22.51^{ \pm} 0.40^{\mathrm{a}, \mathrm{A}}$ \\
\hline \multirow{2}{*}{$\begin{array}{c}\text { Fat content } \\
(\%)\end{array}$} & CF & $34.00^{ \pm} 6.23^{\mathrm{b}, \mathrm{A}}$ & $22.67 \pm 9.84^{\mathrm{a}, \mathrm{A}}$ \\
& MF 50\% & $25.95 \pm 0.92^{\mathrm{ab}, \mathrm{A}}$ & $26.46 \pm 0.87^{\mathrm{a}, \mathrm{A}}$ \\
& $20.50 \pm 3.80^{\mathrm{a}, \mathrm{A}}$ & $18.44^{ \pm} 1.04^{\mathrm{a}, \mathrm{A}}$ \\
\hline \multirow{2}{*}{ Hardness } & CF & $18.28 \pm 0.63^{\mathrm{a}, \mathrm{A}}$ & $16.44 \pm 0.23^{\mathrm{ab}, \mathrm{A}}$ \\
$(\mathrm{kg})$ & MF 50\% & $20.00 \pm 0.26^{\mathrm{a}, \mathrm{A}}$ & $35.48 \pm 2.10^{\mathrm{c}, \mathrm{B}}$ \\
& MF 70\% & $25.64 \pm 2.44^{\mathrm{b}, \mathrm{A}}$ & $18.65 \pm 0.44^{\mathrm{b}, \mathrm{B}}$ \\
\hline
\end{tabular}

Values are expressed as mean $\pm \mathrm{SD}, \mathrm{n}=2$. Values with different lowercase superscript within the same column are significantly different $(\mathrm{P}<0.05)$ while values with different uppercase superscript within the same row are significantly different $(\mathrm{P}<0.05)$.

Generally, microwave frying produced fried beef patty with lower moisture content and oil uptake compared to conventional frying. Theoretically, fried food that has lower moisture content contains higher fat content due to the mass transfer mechanism during the frying process. Some researchers argued that the total volume of oil absorption will be equal to the total volume of water removed (Naik et al., 2017). This would depend on the type of frying technique used to fry the food and the type of food. Contradicting results obtained in this study for microwave frying is due to the higher evaporation rate of water resulted from the pressure generated by microwaves compared to diffusion of oil into food product during conventional frying. Microwave frying promotes water pumping from the inside of the food to the surface (Parikh and Takhar, 2016). The increased temperature and internal pressure were greater than conventional frying and this method also favours moisture escape (Sansano et al., 2018). Hence, the difference between the magnitude of moisture and fat content between conventional and microwave frying was expected since microwave enhances moisture loss significantly and create additional internal pressure to hinder oil diffusion. The result of this study is in accordance with other studies on microwave frying of potato slices which showed a linear relation between moisture and fat content in fried potato slices (Naik et al., 2017).
Differences in oil type used to fry the beef patty insignificantly affect moisture and fat content. Microwave frying with $50 \%$ power level has slightly higher oil absorption than microwave frying with $70 \%$ power level. This is caused by the lower power level which correlates with lower temperature. When magnetron in microwaves stop, there is no electromagnetic energy input, thus the flow of water into the food surface slows down and oil absorption takes place (Pedreschi and Moyano, 2005). On the other hand, theoretically, fried beef patty from conventional frying should have lower moisture content than those of microwave frying. This theory is generally based on plant-based food which contains a higher amount of water and lower amount of fat than animal-based food. In this case, the beef patty itself has $50.73 \%$ and $28.24 \%$ of water and fat initially. Fat inside the beef patty might prevent the heat from the frying oil to be transferred into the structure. Consequently, moisture could not be evaporated out due to insufficient energy from the heat. Furthermore, fat is hydrophobic, thus contributes to the resistance for the moisture to be evaporated out. This might explain the reasons for the small moisture content decrements in conventional frying, CF. Overall, the different types of frying techniques had a greater effect than the use of different types of oil on the moisture and fat content of beef patties. Frying techniques could alter the factors that contribute to the mass transfer mechanism during frying which overcomes any contribution of different types of oil. Thus, a different magnitude of moisture and fat content in animal-based food could be expected from different types of frying techniques.

\subsection{Texture analysis}

The results of texture analysis in term of hardness $(\mathrm{kg})$ of fried beef patties are shown in Table 1. Hardness is the force that is required to attain a given deformation in a product. The initial hardness of raw beef patty is $3.72 \pm 0.02 \mathrm{~kg}$ and based on Table 1, microwave-frying beef patty, MF $50 \%$ using corn oil has the highest value of hardness $(35.48 \pm 2.10 \mathrm{~kg})$ while beef patty of conventional frying, CF using corn oil has the lowest hardness value $(16.44 \pm 0.23 \mathrm{~kg})$.

The result shows that different type of frying methods and different types of oil in microwave frying (MF 50\% and MF 70\%) had significant effects $(p<0.05$ ) on the hardness of beef patties. A higher microwave power level should have a harder texture. Hence, the texture of the beef patty that was fried by microwave is harder than conventional frying. This can be justified by the low moisture content (high moisture loss) of the microwave frying method. The hardness of beef patties that were fried using palm oil increased with the power 
level whereas the hardness of beef patties that were fried using corn oil decreased as microwave power level increased. This may be due to the viscosity of the oil. According to Fasina and Colley (2008), the viscosity of corn oil decreased as temperature increased. Oil with high viscosity tends to have more oil uptake since viscous oil is hard to drip off from food products. Therefore, it will remain inside the food (MPOC, 2012). Since higher microwave power levels promote higher temperature, thus the viscosity of corn oil decreases and less oil was absorbed into the beef patty. Heat can also solubilize connective tissue and provide tenderness in the meat, whereas the hardness or toughness of meat is associated with the denaturation of myofibrillar protein. Besides moisture, fat and protein content are important factors that determine the texture of restructured meat (Serrano et al., 2007). According to the AZMY product of Selangor Food Industry (SFI), the meat content in 700 $\mathrm{g}$ beef patty is $60 \%$. Thus, the high meat content induced the denaturation of myofibrillar protein which provide hardness to the beef patty.

\subsection{Colour analysis}

Colour is an important parameter that needs to be controlled during the frying process besides texture, moisture and oil absorption. In fried product, colour changes resulted from moisture loss, oil uptake, time, the temperature of frying and also a series of Maillard reaction which relies on reducing sugar and amino acid present (Krokida et al., 2001). The results of the colour analysis of beef patties from microwave and conventional frying techniques are shown in Table 2 . The initial colour value for raw beef patties is $58.12 \pm 0.28$ for lightness ( $\left.\mathrm{L}^{*}\right), 21.99 \pm 0.014$ for redness $\left(a^{*}\right)$ and $16.56 \pm 0.02$ for yellowness $\left(b^{*}\right)$. Results shown in Table 2 has revealed the significant effect $(p<0.05)$ of the lightness $\left(\mathrm{L}^{*}\right)$ between three types of frying methods where conventional frying $(\mathrm{CF})$ has the highest $\mathrm{L}^{*}$ values compared to microwave frying (MF).

This is due to uneven oil distribution during conventional frying compared to microwave frying where the cooking oil can cover half the side of the beef patty during frying. The microwavable glass container helps the oil medium to uniformly heat the meat which leads to Maillard reactions. Besides, during frying, myoglobin is oxidized into metmyoglobin which provides brownness to the meat. According to Nikmaram et al. (2011), microwaving meat can alter the colour in a short time. Thus, beef patties that were fried with microwave have darker colour hence, lower $\mathrm{L}^{*}$ value. As for redness $\left(\mathrm{a}^{*}\right)$ value, there is no significant effect $(p>0.05)$ between samples with a different type of frying process. The yellowness $\left(b^{*}\right)$ of conventionally fried beef patties, $\mathrm{CF}$ and microwave frying (MF 50\% and MF $70 \%)$ showed significant effects $(p>0.05)$. The brown colour of beef patty is more dominant compared to other colours. Furthermore, frying using different microwave power level will produce a darker brown beef patty compared to conventional frying. This is because higher microwave power levels will increase the temperature of oil during frying (Naik et al., 2017). Thus, darker colour of meat was produced. Furthermore, the usage of palm oil and corn oil has no significant effect $(p>0.05)$ within similar frying methods for all colour characteristics which shows that the colour attributes of beef patty will not be affected by the types of oil. Both palm oil and corn oil carry a similar chemical reaction which is the Maillard reaction that caused browning to the beef patty.

Table 2. Colour values of fried beef patties

\begin{tabular}{cccc}
\hline Colour & Frying & Palm oil & Corn oil \\
\hline \multirow{2}{*}{ L $^{*}$} & CF & $41.19 \pm 0.54^{\mathrm{c}, \mathrm{A}}$ & $42.94 \pm 0.54^{\mathrm{b}, \mathrm{A}}$ \\
& MF 50\% & $36.51 \pm 2.30^{\mathrm{b}, \mathrm{A}}$ & $33.91 \pm 0.96^{\mathrm{a}, \mathrm{A}}$ \\
& MF 70\% & $32.85 \pm 0.50^{\mathrm{a}, \mathrm{A}}$ & $32.40 \pm 0.40^{\mathrm{a}, \mathrm{A}}$ \\
\hline \multirow{3}{*}{$\mathrm{a}^{*}$} & CF & $16.03 \pm 0.23^{\mathrm{a}, \mathrm{A}}$ & $15.79 \pm 0.04^{\mathrm{a}, \mathrm{A}}$ \\
& MF 50\% & $16.79 \pm 1.28^{\mathrm{a}, \mathrm{A}}$ & $15.64 \pm 0.04^{\mathrm{a}, \mathrm{A}}$ \\
& MF 70\% & $16.12 \pm 0.54^{\mathrm{a}, \mathrm{A}}$ & $15.4 \pm 0.48^{\mathrm{a}, \mathrm{A}}$ \\
\hline \multirow{3}{*}{$\mathrm{b}^{*}$} & CF & $21.25 \pm 0.65^{\mathrm{b}, \mathrm{A}}$ & $21.03 \pm 0.10^{\mathrm{b}, \mathrm{A}}$ \\
& MF 50\% & $14.05 \pm 0.48^{\mathrm{a}, \mathrm{A}}$ & $13.67 \pm 0.86^{\mathrm{a}, \mathrm{A}}$ \\
& MF 70\% & $14.38 \pm 0.34^{\mathrm{a}, \mathrm{A}}$ & $13.39 \pm 0.45^{\mathrm{a}, \mathrm{A}}$ \\
\hline
\end{tabular}

$L^{*}$ : lightness, $a^{*}$ : redness while $b^{*}$ : yellowness. Values are expressed as mean $\pm \mathrm{SD}, \mathrm{n}=2$. Values with different lowercase superscript within the same column are significantly different $(\mathrm{P}<0.05)$ while values with different uppercase superscript within the same row are significantly different $(\mathrm{P}<0.05)$.

\subsection{Cooking yield}

The cooking yield of fried beef patties from microwave and conventional frying techniques is shown in Figure 1. Cooking yield describes the changes in food weight due to moisture loss whether by evaporation, fat absorption or loss and also water adsorption. Cooking yield is used in food formulation to convert the nutritional values of uncooked food into cooked food. The USDA also provide the cooking yield table which describes changes in food since the 1950s.

Based on Figure 1, there is a significant difference $(p<0.05)$ of cooking yield between microwave frying at the power level of $50 \%$ and $70 \%$, MF $50 \%$ and MF $70 \%$ respectively and also the conventional frying, $\mathrm{CF}$. Conventional frying has the highest cooking yield (86.12\% palm oil and $88.60 \%$ corn oil) while MF $70 \%$ has the lowest cooking yield which was $56.05 \%$ for palm oil and $56.13 \%$ for corn oil. Meanwhile, the type of oil does not significantly affect $(p<0.05)$ the cooking yield for all types of frying methods. According to Berry 
(1998), the cooking yield decreased with the increase of fat content. However, according to Table 1, conventional frying has the highest fat content, yet the cooking yield was high. In research conducted by Roseland et al. (2012) on different cuts of beef and pork meats, it turns out that cooking yields were inversely related to the fat content in ground beef products that were studied. Furthermore, there was also no significant effect in ground pork cooking yields among three fat levels in the research (Roseland et al., 2012). According to AlesonCarbonell et al. (2005), cooking yield in meat and meat products is associated with fat and water retention. The grinding process during beef patties production promotes a tender product due to the breakdown of myofibrils and connective tissue in meat. Hence, it promotes weight loss during the cooking process (Kastner and Felicio, 1980).

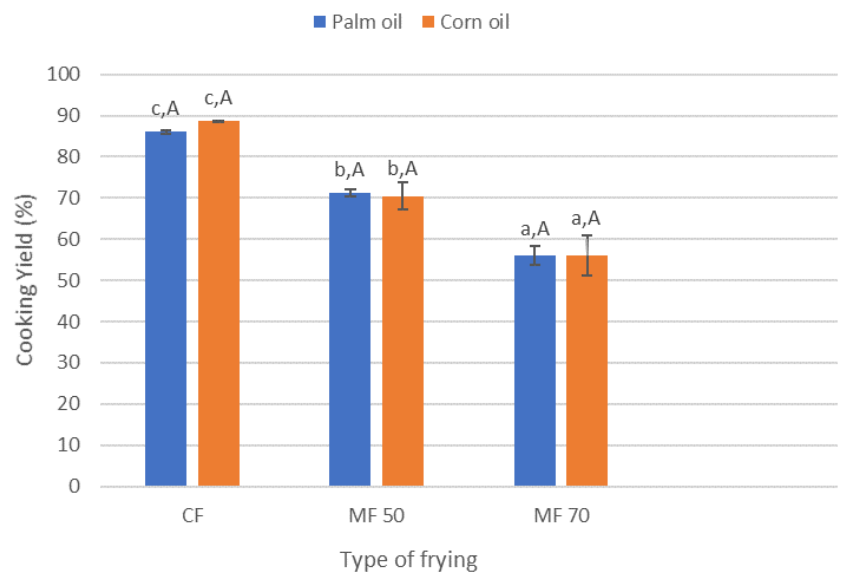

Figure 1. Cooking yield of fried beef patties. Bars with different top lowercase letters are significantly different $(\mathrm{P}<0.05)$ based on the types of frying technique while bars with different top uppercase letters are significantly different $(\mathrm{P}<0.05)$ based on different types of oil.

\section{Conclusion}

Microwave frying has a significant effect on the compositions, textural, colour and cooking yield of the beef patty. In term of textural, colour and cooking yield properties, the conventional frying of beef patty had better quality attributes. However, in this study, microwave frying was found to have the ability to reduce oil absorption compared to conventional frying, but not significantly. A higher microwave power level led to a faster water loss rate which then reduced the moisture content and oil absorption. The use of corn oil and palm oil has no significant effect in all analysis except for textural properties where a significant difference in the hardness of beef patties for the two types of oil was observed.

\section{Conflict of interest}

The authors declare no conflict of interest.

\section{Acknowledgements}

This research was supported by research funding of Short Term Grant Universiti Sains Malaysia (304/ PTEKIND/6313331). The authors would also like to thank the Food Technology Division of the School of Industrial Technology, Universiti Sains Malaysia for supporting and providing the laboratories for this project.

\section{References}

Aleson-Carbonell, L., Fernández-López, J., PérezAlvarez, J.A. and Kuri, V. (2005). Characteristics of beef burger as influenced by various types of lemon albedo. Innovative Food Science and Emerging Technologies, 6(2), 247-255. https:// doi.org/10.1016/j.ifset.2005.01.002

AOAC. (2000). Official Methods of Analysis. 17th ed. Washington, D.C., USA: Association of Official Analytical Chemist.

Berry, B.W. (1998). Color of cooked beef patties as influenced by formulation and final internal temperature. Food Research International, 30(7), 473-478. https://doi.org/10.1016/S0963-9969(98) 00023-4

Bigner-George, M.E. and Berry, B.W. (2000). Thawing prior to cooking affects sensory, shear force, and cooking properties of beef patties. Journal of Food Science, 65(1), 2-8. https://doi.org/10.1111/j.13652621.2000.tb15946.x

Bourne, M.C. (1978). Texture profile analysis. Food Technology, 32(7), 62-66.

Choe, E. and Min, D.B. (2007). Chemistry of deep-fat frying oils. Journal of Food Science, 72(5), 77-86. https://doi.org/10.1111/j.1750-3841.2007.00352.x

Fasina, O.O. and Colley, Z. (2008). Viscosity and specific heat of vegetable oils as a function of temperature: $35^{\circ} \mathrm{C}$ to $180^{\circ} \mathrm{C}$. International Journal of Food Properties, 11(4), 738-746. https:// doi.org/10.1080/10942910701586273

Food Safety. (2009). Safe Minimum Cooking Temperatures. Retrieved on April 7, 2019, from https://www.foodsafety.gov/keep/charts/ mintemp.html

Kastner, C.L. and Felicio, P. (1980). Tratamentos que influem na maciez da carne bovina no periodo posabate. Boletim Tecnico - Centro de Tecnologia Da Carne. Instituto de Tecnologia de Alimentos, 5, 3164. [In Spanish].

Krokida, M.K., Oreopoulou, V., Maroulis, Z.B. and Marinos-Kouris, D. (2001). Effect of pre-drying on quality of french fries. Journal of Food Engineering, 49(4), 347-354. https://doi.org/10.1016/S0260-8774 (00)00233-8 
Laack, R.L.J.M., Berry, B.W. and Solomon, M.B. (1996). Variations in internal color of cooked beef patties. Journal of Food Science, 61(2), 410-414. https://doi.org/10.1111/j.1365-2621.1996.tb14205.x

May, C.Y. and Nesaretnam, K. (2014). Research advancements in palm oil nutrition. European Journal of Lipid Science and Technology, 116(10), 1301-1315. https://doi.org/10.1002/ejlt.201400076

MPOC (Malaysian Palm Oil Council). (2012). The Oil Palm. Retrieved on April 7, 2019 from MPOC website: http://www.mpoc.org.my/FAQs.aspx

Naik, K.M., Lakshmi Bala, K. and Srinivas, D. (2017). Study on optimisation of microwave frying of potato slices. International Journal of Pure and Applied Bioscience, 5(4), 1207-1218. https:// doi.org/10.18782/2320-7051.5545

Nikmaram, P., Mohamad, S.Y. and Zahra, E. (2011). Effect of cooking methods on chemical composition, quality and cook loss of camel muscle (Longissimus dorsi) in comparison with veal. African Journal of Biotechnology, 10(51), 10478-10483. https:// doi.org/10.5897/AJB10.2534

Parikh, A. and Takhar, P.S. (2016). Comparison of microwave and conventional frying on quality attributes and fat content of potatoes. Journal of Food Science, 81(11), 2743-2755. https:// doi.org/10.1111/1750-3841.13498

Pedreschi, F. and Moyano, P. (2005). Oil uptake and texture development in fried potato slices. Journal of Food Engineering, 70(4), 557-563. https:// doi.org/10.1016/j.jfoodeng.2004.10.010

Roseland, J.M., Williams, J.R., Duvall, M., Showell, B., Patterson, K.Y., Douglas, L.W., Daniel, M. and Holden, J.M. (2012). Effect of meat type and cooking method on cooking yields. Agricultural Research Service, US Department of Agriculture. Retrieved on April 7, 2019 from https:// www.ars.usda.gov/ARSUserFiles/80400525/

Articles/ICoMST2012_MeatCookingYield2.pdf

Sansano, M., De Los Reyes Cánovas, R., Grau, A.M. and Heredia Gutiérrez, A.B. (2018). Effect of microwave frying on acrylamide generation, mass transfer, color, and texture in french fries. Food and Bioprocess Technology, 11(10), 1934-1939. https:// doi.org/10.1007/s11947-018-2144-z

Serdaroğlu, M. (2006). Improving low fat meatball characteristics by adding whey powder. Meat Science, 72(1), 155-163. https://doi.org/10.1016/ j.meatsci.2007.03.017

Serrano, A., Librelotto, J., Cofrades, S., Sánchez-Muniz, F.J. and Jiménez-Colmenero, F. (2007). Composition and physicochemical characteristics of restructured beef steaks containing walnuts as affected by cooking method. Meat Science, 77(3), 304-313. doi: https://doi.org/10.1016/j.meatsci.2007.03.017

Shaker, M.A. (2015). Comparison between traditional deep-fat frying and air-frying for production of healthy fried potato strips. International Food Research Journal, 22(4), 1557-1563.

$\mathrm{Su}$, Y., Zhang, M., Zhang, W., Adhikari, B. and Yang, Z. (2016). Application of novel microwave-assisted vacuum frying to reduce the oil uptake and improve the quality of potato chips. LWT - Food Science and Technology, 73, 490-497. https://doi.org/10.1016/ j.lwt.2016.06.047

Tornberg, E. (2005). Effects of heat on meat proteins Implications on structure and quality of meat products. Meat Science, 70(3), 493-508. https:// doi.org/10.1016/j.meatsci.2004.11.021

Wong, W.C., Fung Pui, C., Zainazor, T., Chilek, T., Noorlis, A., Tang, J.Y.H., Nakaguchi, Y. and Radu, S. (2011). Survival of Listeria monocytogenes during frying of chicken burger patties. Food and Nutrition Sciences, 2, 471-475. https://doi.org/10.4236/ fns.2011.25067

Ziaiifar, A.M., Achir, N., Courtois, F., Trezzani, I. and Trystram, G. (2008). Review of mechanisms, conditions, and factors involved in the oil uptake phenomenon during the deep-fat frying process. International Journal of Food Science and Technology, 43(8), 1410-1423. https:// doi.org/10.1111/j.1365-2621.2007.01664.x

Zzaman, W., Chantrong, P., Idrus, N.F.M. and Yang, T.A. (2013). Effect of different cooking methods on the quality attribute of beef burgers. Journal of Applied Science, 9(4), 2538-2547 